\title{
Dinâmica de nutrientes na solução do solo em pomar fertirrigado de citros
}

\author{
Thais Regina de Souza(1), Roberto Lyra Villas Bôas(2), José Antônio Quaggio(1), Leandro Caixeta Salomão(2) \\ e Letícia Cecília Foratto(2)
}

\begin{abstract}
(1)Instituto Agronômico, Centro de Solos e Recursos Ambientais, Avenida Barão de Itapura, no 1.481, CEP $13012-970$ Campinas, SP. E-mail: tr_souza@yahoo.com.br, quaggio@iac.sp.gov.br (2)Universidade Estadual Paulista, Departamento de Recursos Naturais, Rua José Barbosa de Barros, no 1.780, CEP 18610-307 Botucatu, SP. E-mail: rlvboas@fca.unesp.br, salomaoleandro@gmail.com, Ic_foratto@yahoo.com.br
\end{abstract}

Resumo - O objetivo deste trabalho foi avaliar a dinâmica de nutrientes na solução do solo após a aplicação, via fertirrigação, de nitrogênio, fósforo e potássio a laranjeiras. O experimento foi realizado entre setembro de 2007 e outubro de 2009, em pomares de laranjeiras 'Valência' e 'Hamlin', enxertadas sobre citrumeleiro 'Swingle'. Foram avaliadas cinco doses de N, $\mathrm{P}_{2} \mathrm{O}_{5}$ e $\mathrm{K}_{2} \mathrm{O}(0,25,50,100$ e $200 \%$ da dose recomendada). A solução do solo foi extraída a 30 e $60 \mathrm{~cm}$ de profundidade, com o auxílio de extratores com cápsulas porosas. Foram realizadas 11 avaliações durante o período experimental, com as extrações iniciadas após 12 horas das fertirrigações. $\mathrm{O}$ aumento das doses reduziu o $\mathrm{pH}$ ( $\mathrm{pH} \sim 3,5$, na maior dose), e aumentou a condutividade elétrica ( $\mathrm{CE} \sim 1,5 \mathrm{dS} \mathrm{m}^{-1}$, na maior dose) e os teores de $\mathrm{NH}_{4}, \mathrm{NO}_{3}, \mathrm{P}, \mathrm{K}$, Mn e $\mathrm{Zn}$ na solução do solo, nas duas profundidades amostradas. Nos meses com maior precipitação pluvial, houve perda potencial de nutrientes por lixiviação, pois maiores concentrações de $\mathrm{NO}_{3}, \mathrm{~K}$ e B foram observadas à profundidade de $60 \mathrm{~cm}$. A análise da solução do solo, obtida por extratores com cápsula de cerâmica porosa, pode ser considerada ferramenta auxiliar para monitorar e avaliar a disponibilidade de nutrientes às plantas.

Termos para indexação: Citrus sinensis, acidificação, cápsula porosa, extrator de solução, fertirrigação, lixiviação.

\section{Nutrient dynamics in soil solution in a fertigated citrus orchard}

\begin{abstract}
The objective of this work was to evaluate nutrient dynamics in soil solution after fertigated application of nitrogen, phosphorus, and potassium to orange trees. The experiment was carried out from September 2007 to October 2009, in 'Valência' and 'Hamlin' orange orchards grafted onto citrumelo 'Swingle' rootstock. Five doses of $\mathrm{N}, \mathrm{P}_{2} \mathrm{O}_{5}$ and $\mathrm{K}_{2} \mathrm{O}(0,25,50,100$ and $200 \%$ of the recommended dose) were evaluated. Soil solution was extracted from 30 and $60 \mathrm{~cm}$ soil depths using extractors with porous cups. Eleven evaluations were done during the experimental period, with extractions beginning 12 hours after fertigation. Increasing nutrient doses decreased $\mathrm{pH}\left(\mathrm{pH} \sim 3.5\right.$, at the highest dose), and increased electrical conductivity $\left(\mathrm{CE} \sim 1.5 \mathrm{dS} \mathrm{m}^{-1}\right.$, at the highest dose) and the amounts of $\mathrm{NH}_{4}, \mathrm{NO}_{3}, \mathrm{P}, \mathrm{K}, \mathrm{Mn}$, and $\mathrm{Zn}$ in the soil solution, in both sampled depths. In the months with heavier rainfall, there was nutrient potential losses by leaching, since higher concentrations of $\mathrm{NO}_{3}, \mathrm{~K}$, and $\mathrm{B}$ were observed at the $60 \mathrm{~cm}$ soil depth. Soil solution analysis, obtained by extractors with porous ceramic cups, can be considered an auxiliary tool for monitoring and assessing nutrient availability to plants.
\end{abstract}

Index terms: Citrus sinensis, acidification, porous cups, solution extractor, fertigation, leaching.

\section{Introdução}

A área irrigada na citricultura brasileira vem crescendo rapidamente na última década, com predominância do uso da irrigação localizada e associada à técnica de fertirrigação. A principal vantagem da fertirrigação é o ganho de eficiência no uso dos fertilizantes, em razão da maior facilidade de parcelamento da adubação, que permite melhor ajuste no fornecimento de nutrientes com a demanda da planta, nos diferentes estádios de desenvolvimento. A fertirrigação contribui também para a redução das perdas por lixiviação (Duenhas et al., 2002). Além disso, o monitoramento da concentração de nutrientes na solução do bulbo úmido permite ajustar a quantidade aplicada antes da ocorrência de deficiências minerais.

Para Barros et al. (2010), quando se utiliza a fertirrigação, é importante acompanhar a dinâmica e a distribuição dos nutrientes no perfil do solo, pois isto permite estabelecer ou ajustar a aplicação dos

Pesq. agropec. bras., Brasília, v.47, n.6, p.846-854, jun. 2012 
fertilizantes, além de prevenir danos ambientais como a salinização dos solos e a contaminação das águas.

Dessa forma, o conhecimento da composição química da solução do solo poderá fornecer subsídios importantes no manejo da fertirrigação. Contudo, informações da literatura sobre níveis adequados de nutrientes na solução do solo, para a cultura de citros no campo e durante o ciclo de cultivo, são escassas. Segundo Raij (1991), embora se reconheça a importância da solução do solo para a nutrição vegetal, seu estudo é difícil, em razão da complexidade da fase de extração. Wolt (1994) comenta que há diversos métodos de extração da solução do solo: deslocamento de solução em coluna, pela adição ou retirada de gases ou adição de líquidos; centrifugação à alta e à baixa pressão; câmera de pressão; vácuo no extrato saturado e soluções aquosas; métodos de adsorção molecular; e uso de extratores providos de cápsulas porosas.

A utilização de extratores de cápsulas porosas, para extrair a solução do solo, é bastante difundida, principalmentepor seumanejo fácil, custo relativamente baixo e pelo fato de o extrato obtido não requerer tratamentos prévios às determinações físicoquímicas (Moraes \& Dynia, 1990). Para Silva (2002), o monitoramento da solução com o uso de extratores providos de cápsulas de cerâmica porosa auxilia na tomada de decisão da quantidade de fertilizantes a ser aplicada por fertirrigação.

A amostragem e a realização da análise química periódica de solo, com a finalidade de acompanhar as concentrações dos íons na solução durante as fases de crescimento e desenvolvimento da cultura, são inviáveis economicamente, ainda mais em sistemas de fertirrigação, que permitem aplicações frequentes de nutrientes ao solo. Portanto, há necessidade de métodos diagnósticos mais dinâmicos.

O objetivo deste trabalho foi avaliar a dinâmica de nutrientes na solução do solo após a aplicação, via fertirrigação, de nitrogênio, fósforo e potássio a laranjeiras.

\section{Material e Métodos}

O experimento foi conduzido entre setembro de 2007 e outubro de 2009, na Fazenda Emú, da empresa Citrovita, localizada em Reginópolis, SP, $\left(21^{\circ} 49^{\prime} 45^{\prime \prime}\right.$, $49^{\circ} 08^{\prime} 27^{\prime \prime} \mathrm{W}$ e altitude de $460 \mathrm{~m}$ ). O macroclima da região, segundo a classificação de Köppen, é do tipo Cwa, mesotérmico tropical de altitude, com inverno seco e temperatura média do mês mais quente superior a $22^{\circ} \mathrm{C}$.

$\mathrm{O}$ experimento foi instalado em áreas próximas com laranjeiras 'Valência' e 'Hamlin', ambas enxertadas sobre citrumeleiro 'Swingle'. Foi montado um único sistema de fertirrigação para ambas as variedades. $\mathrm{O}$ espaçamento de plantio foi de $7 \mathrm{x} 4 \mathrm{~m}$ e, no período de coleta das amostras de solução do solo, as plantas tinham entre cinco e seis anos de idade.

Antes do início do experimento, as amostras de solo, retiradas da área experimental na camada de 0-20 cm, tinham as seguintes características químicas, conforme Raij et al. (2001): $\mathrm{pH}\left(\mathrm{CaCl}_{2}\right), 5,0 ; \mathrm{MO}, 9 \mathrm{~g} \mathrm{dm}^{-3}$; $\mathrm{P}$ (resina), $57 \mathrm{mg} \mathrm{dm}^{-3} ; 21,3,14,5,22$ e 44 mmol $_{\mathrm{c}} \mathrm{dm}^{-3}$ de $\mathrm{H}+\mathrm{Al}, \mathrm{K}, \mathrm{Ca}, \mathrm{Mg}, \mathrm{SB}, \mathrm{CTC}$, respectivamente; e $51 \%$ de saturação por bases. A textura do solo na camada de 0-60 cm era arenosa, com teor de argila inferior a $15 \%$.

Os tratamentos foram constituídos por cinco doses de $\mathrm{N}, \mathrm{P}_{2} \mathrm{O}_{5}$ e $\mathrm{K}_{2} \mathrm{O}$, aplicadas via fertirrigação. A dose completa (100\%), definida com base no histórico de análises de solo e folha, obtidos na fazenda, e também no rendimento esperado do talhão, correspondeu a 140,40 e $130 \mathrm{~kg} \mathrm{ha}^{-1}$ por ano de $\mathrm{N}, \mathrm{P}_{2} \mathrm{O}_{5}$ e $\mathrm{K}_{2} \mathrm{O}$, respectivamente, conforme recomendação de Quaggio et al. (2005). Assim, foram estabelecidos os seguintes tratamentos: T1, somente irrigado, sem aplicação de nutrientes; T2, fertirrigado com $25 \%$ da dose de N, $\mathrm{P}_{2} \mathrm{O}_{5}$ e $\mathrm{K}_{2} \mathrm{O}$; T3, fertirrigado com $50 \%$ da dose de $\mathrm{N}$, $\mathrm{P}_{2} \mathrm{O}_{5}$ e $\mathrm{K}_{2} \mathrm{O}$; T4, fertirrigado com $100 \%$ da dose de $\mathrm{N}$, $\mathrm{P}_{2} \mathrm{O}_{5}$ e $\mathrm{K}_{2} \mathrm{O}$; e T5, fertirrigado com $200 \%$ da dose de $\mathrm{N}$, $\mathrm{P}_{2} \mathrm{O}_{5}$ e $\mathrm{K}_{2} \mathrm{O}$.

As fontes de $\mathrm{N}, \mathrm{P}$ e $\mathrm{K}$ utilizadas foram, respectivamente, nitrato de amônio, ácido fosfórico e cloreto de potássio branco. O parcelamento do $\mathrm{N}$ e do K, durante a fertirrigação, foi feito em 34 semanas, desde o início do mês de setembro até o fim do mês de abril de cada safra, em duas aplicações semanais, no total de 68 aplicações. Da dose total indicada em cada tratamento, $25 \%$ foi aplicada entre setembro e outubro, $50 \%$ entre os meses de novembro a março, e os $25 \%$ restantes foram aplicados em abril. O fósforo foi aplicado no início da safra. Os micronutrientes B, $\mathrm{Mn}$ e $\mathrm{Zn}$ foram aplicados via fertirrigação nas formas de ácido bórico, sulfato de manganês e sulfato de zinco, nas doses 10,10 e $8 \mathrm{~kg} \mathrm{ha}^{-1}$ ao ano, respectivamente. $\mathrm{O}$ parcelamento destas seguiu o mesmo do $\mathrm{N}$ e do $\mathrm{K}$, porém em doses iguais para todos os tratamentos. O período de estresse hídrico, em que as plantas não 
receberam água e nutrientes com a finalidade de indução floral, foi de maio a julho.

As parcelas experimentais foram constituídas por três linhas com 12 plantas, em que as dez da linha central foram designadas para as avaliações das variáveis de interesse para o experimento. As duas linhas laterais e as duas plantas nos extremos da linha central formavam a bordadura, no total de 36 árvores por parcela. Todo o experimento ocupou uma área de aproximadamente 4,0 ha. O delineamento estatístico empregado foi o de blocos ao acaso, com quatro repetições.

Para o sistema de irrigação, as parcelas foram dotadas de linhas simples de tubos gotejadores, instaladas ao lado dos troncos das árvores, paralelamente à linha de plantio. O emissor utilizado foi do tipo RAM (Netafim), com vazão de 2,3 L por hora e espaçamento entre emissores de $0,6 \mathrm{~m}$. O bulbo úmido atingia cerca de $0,8 \mathrm{~m}$ de largura de faixa molhada. A injeção dos fertilizantes foi feita através do injetor Venturi.

O manejo da irrigação foi realizado com base na medida diária da evaporação, por meio de tanque classe A, tendo-se obtido a evapotranspiração potencial (ETP) e a evapotranspiração da cultura (ETc), conforme Allen et al. (1998). O experimento também foi monitorado com emprego de três baterias de tensiômetros por variedade, cada uma formada por três tensiômetros, colocados a profundidades de: 30 , 60 e $90 \mathrm{~cm}$. O monitoramento foi realizado de acordo com a curva de retenção da água no solo, obtida de acordo com Camargo et al. (1986). Foi adotado turno de irrigação fixo, com duas aplicações semanais, de acordo com as fertirrigações. A lâmina média diária aplicada foi de $3,5 \mathrm{~mm}$.

Para extração da solução do solo, foram instalados 80 extratores na área experimental (40 por variedade), dos quais dois na região central de cada parcela, à profundidade de 30 e $60 \mathrm{~cm}$, a $20 \mathrm{~cm}$ de distância horizontal de um emissor e sob a projeção da copa das árvores.

Cada extrator de solução do solo foi composto de um tubo de PVC (12,7 mm de diâmetro e 40 e $70 \mathrm{~cm}$ de comprimento, respectivamente, para os extratores instalados a 30 e $60 \mathrm{~cm}$ de profundidade, sendo que, aproximadamente $13 \mathrm{~cm}$ do tubo de PVC ficava exposto na superfície do solo), conectado, na extremidade inferior, a uma cápsula de cerâmica porosa (60 $\mathrm{mm}$ de comprimento e $19 \mathrm{~mm}$ de diâmetro). O meio da cápsula foi locado na profundidade em que se desejava avaliar a solução do solo. Na extremidade superior, o tubo foi vedado com uma rolha atravessada por dois tubos de nylon: em um deles, era aplicado vácuo e, no outro, ficava conectada uma seringa pela qual se coletava a solução.

Foram feitas extrações de solução do solo em novembro de 2007, janeiro, fevereiro, março, abril, outubro e novembro de 2008 e em janeiro, março, abril e maio de 2009, no total de 11 coletas. As extrações foram iniciadas cerca de 12 horas após uma fertirrigação, tendo-se aplicado, nos extratores, um vácuo de $80 \mathrm{kPa}$, com o auxílio de bomba de vácuo manual. A coleta da solução foi efetuada seis horas depois da aplicação do vácuo.

Na solução do solo extraída, foram determinados, diretamente, sem filtragem ou digestão, o pH, a condutividade elétrica (CE), o nitrogênio mineral $\left(\mathrm{NH}_{4}\right.$ e $\mathrm{NO}_{3}$ ) e os macro e micronutrientes, conforme Raij et al. (2001).

Em setembro de 2007 e de 2008, foram aplicados, de forma localizada e superficial, na largura da faixa molhada, 1,0 e 1,5 $\mathrm{Mg} \mathrm{ha}^{-1}$ de calcário, respectivamente, com poder de reação e neutralização de $90 \%$.

A produção, em $\mathrm{kg}$ por planta, foi quantificada a partir da massa e do número de frutos produzidos por planta. Posteriormente, de acordo com o número de plantas por hectare, foi calculada a produtividade $\left(\mathrm{Mg} \mathrm{ha}^{-1}\right)$ dos pomares. Para tanto, foi determinado o número total de frutos de cinco plantas, em cada parcela. Para a avaliação da massa dos frutos, foram consideradas as dez plantas úteis da parcela, e foram retirados, por planta, quatro frutos - dois externos e dois internos -, tendo-se alternado a coleta entre os quatro quadrantes e na altura mediana da planta, no total de 40 frutos por parcela, pesados individualmente. A colheita de frutos da laranjeira 'Hamlin', na safra 2008/2009, foi realizada em julho de 2009, e a da 'Valência' em outubro de 2009.

Os dados foram submetidos à análise de variância e de regressão linear e polinomial. As médias foram comparadas entre profundidades e variedades, pelo teste Tukey a 5\% de probabilidade. A análise estatística foi realizada com o programa Sisvar (Ferreira, 2008).

\section{Resultados e Discussão}

$\mathrm{O}$ pH da solução do solo diminuiu com o aumento da dose aplicada de nutrientes (Tabela 1). Essa variação ocorreu de maneira similar, nas duas profundidades amostradas (30 e $60 \mathrm{~cm}$ ) e na área das duas variedades de 
copa estudadas, tendo atingido valores médios em torno de 3,5 no tratamento com as maiores doses de fertilizantes (T5). Como a fertirrigação foi feita por gotejamento, o fertilizante manteve-se concentrado na zona de molhamento, que é um volume de solo restrito. Além disso, as fontes de nitrogênio e fósforo utilizadas têm reação ácida e, portanto, quanto maior a dose aplicada, maior o efeito acidificante na solução do solo. Souza et al. (2006) trabalharam por 36 meses com fertirrigação em citros, e observaram decréscimo acentuado do $\mathrm{pH}$ na solução do solo. Os autores alertaram para os perigos da acidificação, em regiões tropicais, quando são utilizadas fontes de fertilizantes de reação ácida.

Os valores de condutividade elétrica da solução do solo aumentaram conforme o aumento da dose aplicada de fertilizantes (Tabela 1). Esse aumento também ocorreu de modo similar aos 30 e $60 \mathrm{~cm}$ de profundidade. Valores de condutividade elétrica acima do limiar de tolerância da cultura podem afetar a produção. As fontes de nitrogênio e potássio utilizadas

Tabela 1. Resultado da análise da solução do solo, nas profundidades de 30 e $60 \mathrm{~cm}$, em função dos tratamentos, em pomares com laranjeira 'Valência' e 'Hamlin', referente à média dos 11 meses de amostragem.

\begin{tabular}{|c|c|c|c|c|c|c|c|c|c|c|c|c|c|c|}
\hline Tratamento $^{(1)}$ & $\mathrm{pH}$ & $\begin{array}{c}\mathrm{CE} \\
\left(\mathrm{dS} \mathrm{m}^{-1}\right)\end{array}$ & N-NH & $\mathrm{N}-\mathrm{NO}_{3}$ & $\mathrm{~K}$ & $\mathrm{Ca}$ & $\begin{array}{c}\mathrm{Mg} \\
\left(\mathrm{mg} \mathrm{L}^{-1}\right)\end{array}$ & $P$ & $\mathrm{~S}$ & B & $\mathrm{Cu}$ & $\mathrm{Fe}$ & $\mathrm{Mn}$ & Zn \\
\hline & \multicolumn{14}{|c|}{ 'Valência', profundidade $30 \mathrm{~cm}$} \\
\hline $\mathrm{T} 1(0 \%)$ & 5,7 & 0,2 & 7,5 & 6,9 & 9,1 & 8,2 & 3,0 & 1,3 & 12,4 & 0,5 & 0,1 & 0,02 & 1,0 & 1,6 \\
\hline T2 $(25 \%)$ & 5,2 & 0,4 & 7,1 & 13,6 & 13,5 & 18,2 & 7,3 & 1,2 & 17,8 & 1,8 & 0,1 & 0,02 & 1,9 & 2,5 \\
\hline T3 (50\%) & 3,8 & 0,7 & 7,7 & 34,9 & 40,5 & 28,0 & 8,2 & 1,1 & 19,7 & 2,9 & 0,2 & 0,02 & 5,2 & 5,5 \\
\hline $\mathrm{T} 4(100 \%)$ & 3,6 & 1,0 & 26,9 & 78,5 & 62,8 & 31,6 & 9,3 & 2,6 & 18,4 & 3,6 & 0,3 & 0,02 & 6,8 & 6,6 \\
\hline T5 $(200 \%)$ & 3,3 & 1,6 & 67,3 & 102,9 & 122,0 & 22,0 & 6,8 & 8,5 & 15,5 & 3,5 & 0,2 & 0,03 & 7,0 & 7,6 \\
\hline Tratamento & $117,9^{* *}$ & $106,0 * *$ & $40,4^{* *}$ & $78,2 * *$ & $97,3 * *$ & $15,4 * *$ & $7,1 * *$ & $36,3 * *$ & $1,0^{\mathrm{ns}}$ & $27,5 * *$ & $7,6^{* *}$ & $5,4^{* *}$ & $34,3 * *$ & $24,3^{* *}$ \\
\hline Regressão & $\mathrm{Q}^{* *}$ & $\mathrm{~L}^{* *}$ & $\mathrm{~L}^{* *}$ & $\mathrm{~L}^{* *}$ & $\mathrm{~L}^{* *}$ & $\mathrm{Q}^{* *}$ & $\mathrm{Q}^{* *}$ & $\mathrm{~L}^{* *}$ & $\mathrm{Q}^{\mathrm{ns}}$ & $\mathrm{Q}^{* *}$ & $\mathrm{Q}^{* *}$ & $\mathrm{~L}^{* *}$ & $\mathrm{Q}^{* *}$ & $\mathrm{Q}^{* *}$ \\
\hline $\mathrm{R}^{2}$ & 0,93 & 0,99 & 0,94 & 0,93 & 0,99 & 0,97 & 0,91 & 0,88 & 0,74 & 0,99 & 0,81 & 0,71 & 0,96 & 0,95 \\
\hline \multirow[t]{2}{*}{$\begin{array}{l}\text { Média }^{(2)} \\
\end{array}$} & $4,3 \mathrm{Ab}$ & $0,8 \mathrm{Aa}$ & $23,3 \mathrm{Aa}$ & $47,4 \mathrm{Aa}$ & $49,6 \mathrm{Aa}$ & $21,6 \mathrm{Aa}$ & $6,9 \mathrm{Aa}$ & $2,9 \mathrm{Ab}$ & $16,8 \mathrm{Aa}$ & $2,5 \mathrm{Aa}$ & $0,2 \mathrm{Ab}$ & $0,02 \mathrm{Aa}$ & $4,4 \mathrm{Aa}$ & $4,8 \mathrm{Aa}$ \\
\hline & \multicolumn{14}{|c|}{ 'Valência', profundidade $60 \mathrm{~cm}$} \\
\hline T1 (0\%) & 5,6 & 0,1 & 7,1 & 10,1 & 11,2 & 3,3 & 1,6 & 0,4 & 5,3 & 0,5 & 0,1 & 0,02 & 0,9 & 1,1 \\
\hline $\mathrm{T} 2(25 \%)$ & 5,0 & 0,3 & 6,8 & 16,3 & 13,4 & 13,7 & 4,9 & 0,1 & 13,3 & 1,7 & 0,2 & 0,02 & 2,8 & 3,2 \\
\hline T3 $(50 \%)$ & 3,8 & 0,6 & 6,7 & 43,3 & 41,3 & 17,0 & 6,4 & 0,3 & 11,0 & 2,1 & 0,2 & 0,01 & 4,0 & 3,8 \\
\hline T4 (100\%) & 3,4 & 1,0 & 19,2 & 63,7 & 50,7 & 18,8 & 7,9 & 2,3 & 19,4 & 3,1 & 0,2 & 0,03 & 5,8 & 5,0 \\
\hline T5 (200\%) & 3,5 & 1,5 & 50,8 & 145,5 & 122,1 & 18,7 & 8,8 & 2,0 & 12,8 & 2,1 & 0,1 & 0,02 & 7,4 & 6,2 \\
\hline Tratamento & $202,4 * *$ & $149,1^{* *}$ & $40,3 * *$ & $45,5^{* *}$ & $101,9 * *$ & $16,0 * *$ & $12,7 * *$ & $8,1 * *$ & $3,4^{*}$ & $39,0^{* *}$ & $5,8^{* *}$ & $7,7 * *$ & $27,2 * *$ & $20,4^{* *}$ \\
\hline Regressão & $\mathrm{Q}^{* *}$ & $\mathrm{~L}^{* *}$ & $\mathrm{~L}^{* *}$ & $\mathrm{~L}^{* *}$ & $\mathrm{~L}^{* *}$ & $\mathrm{Q}^{* *}$ & $\mathrm{Q}^{* *}$ & $\mathrm{~L}^{* *}$ & $\mathrm{Q}^{* *}$ & $\mathrm{Q}^{* *}$ & $\mathrm{Q}^{* *}$ & $\mathrm{~L} * *$ & $\mathrm{Q}^{* *}$ & $\mathrm{Q}^{* *}$ \\
\hline$\underline{\mathrm{R}^{2}}$ & 0,97 & 0,97 & 0,93 & 0,99 & 0,97 & 0,89 & 0,96 & 0,63 & 0,81 & 0,98 & 0,83 & 0,30 & 0,99 & 0,97 \\
\hline \multirow[t]{2}{*}{ Média $^{(2)}$} & $4,2 \mathrm{Ab}$ & $0,7 \mathrm{Aa}$ & $18,1 \mathrm{Aa}$ & $55,8 \mathrm{Aa}$ & $47,4 \mathrm{Aa}$ & $14,3 \mathrm{Ba}$ & $5,9 \mathrm{Aa}$ & $1,0 \mathrm{Ba}$ & $12,3 \mathrm{Aa}$ & $1,9 \mathrm{Aa}$ & $0,2 \mathrm{Aa}$ & $0,02 \mathrm{Aa}$ & $4,2 \mathrm{Aa}$ & $3,9 \mathrm{Ba}$ \\
\hline & \multicolumn{14}{|c|}{ 'Hamlin', profundidade $30 \mathrm{~cm}$} \\
\hline $\mathrm{T} 1(0 \%)$ & 6,1 & 0,1 & 6,4 & 11,5 & 7,6 & 5,5 & 1,3 & 2,3 & 3,8 & 0,7 & 0,1 & 0,02 & 0,5 & 1,5 \\
\hline T2 (25\%) & 5,2 & 0,4 & 8,5 & 22,6 & 20,1 & 15,0 & 5,9 & 1,8 & 5,0 & 2,0 & 0,2 & 0,02 & 2,5 & 2,6 \\
\hline T3 (50\%) & 4,6 & 0,6 & 7,7 & 31,1 & 28,4 & 18,0 & 7,5 & 2,6 & 4,5 & 2,1 & 0,2 & 0,02 & 4,2 & 4,1 \\
\hline T4 (100\%) & 4,0 & 0,9 & 23,3 & 52,9 & 58,1 & 20,4 & 5,5 & 8,6 & 4,0 & 2,3 & 0,2 & 0,02 & 4,5 & 3,5 \\
\hline T5 (200\%) & 3,6 & 1,5 & 59,8 & 97,4 & 85,7 & 28,1 & 5,2 & 13,4 & 10,2 & 2,2 & 0,2 & 0,02 & 4,9 & 5,0 \\
\hline Tratamento & $90,3 * *$ & $91,7 * *$ & $46,1^{* *}$ & $52,9 * *$ & $40,0 * *$ & $22,5 * *$ & $16,6^{* *}$ & $22,5 * *$ & $12,7^{* *}$ & 12,0 ** & $2,9^{*}$ & $1,5^{\mathrm{ns}}$ & $19,6 * *$ & $9,8^{* *}$ \\
\hline Regressão & $\mathrm{Q}^{* *}$ & $\mathrm{~L}^{* *}$ & $\mathrm{~L}^{* *}$ & $\mathrm{~L}^{* *}$ & $\mathrm{~L}^{* *}$ & $\mathrm{~L}^{* *}$ & $\mathrm{Q}^{* *}$ & $\mathrm{~L}^{* *}$ & $\mathrm{Q}^{* *}$ & $\mathrm{Q}^{* *}$ & $\mathrm{~L}^{*}$ & $\mathrm{~L}^{\mathrm{ns}}$ & $\mathrm{Q}^{* *}$ & $\mathrm{~L}^{* *}$ \\
\hline $\mathrm{R}^{2}$ & 0,99 & 0,99 & 0,94 & 0,99 & 0,97 & 0,86 & 0,54 & 0,93 & 0,93 & 0,77 & 0,42 & 0,20 & 0,93 & 0,75 \\
\hline \multirow[t]{2}{*}{$\mathrm{Média}^{(2)}$} & $4,7 \mathrm{Aa}$ & $0,7 \mathrm{Aa}$ & $21,2 \mathrm{Aa}$ & $43,1 \mathrm{Aa}$ & $40,0 \mathrm{Aa}$ & $17,4 \mathrm{Ab}$ & $5,1 \mathrm{Ab}$ & $5,6 \mathrm{Aa}$ & $5,5 \mathrm{Ab}$ & $1,9 \mathrm{Ab}$ & $0,2 \mathrm{Aa}$ & $0,02 \mathrm{Aa}$ & $3,3 \mathrm{Ab}$ & $3,4 \mathrm{Ab}$ \\
\hline & \multicolumn{14}{|c|}{ 'Hamlin', profundidade $60 \mathrm{~cm}$} \\
\hline $\mathrm{T} 1(0 \%)$ & 6,3 & 0,1 & 9,4 & 10,1 & 10,1 & 3,4 & 0,8 & 0,7 & 7,3 & 0,6 & 0,1 & 0,02 & 0,4 & 0,9 \\
\hline $\mathrm{T} 2(25 \%)$ & 5,3 & 0,3 & 8,3 & 23,6 & 18,4 & 14,7 & 6,2 & 0,7 & 7,2 & 2,6 & 0,1 & 0,03 & 3,2 & 2,3 \\
\hline $\mathrm{T} 3(50 \%)$ & 5,1 & 0,4 & 7,4 & 25,6 & 18,7 & 18,5 & 4,4 & 0,6 & 4,7 & 1,5 & 0,1 & 0,02 & 3,8 & 2,7 \\
\hline $\mathrm{T} 4(100 \%)$ & 4,2 & 1,0 & 16,9 & 61,4 & 48,6 & 21,6 & 9,3 & 0,8 & 4,3 & 1,7 & 0,4 & 0,03 & 5,1 & 4,3 \\
\hline $\mathrm{T} 5(200 \%)$ & 3,7 & 1,4 & 31,2 & 91,6 & 86,1 & 27,9 & 10,6 & 0,9 & 5,3 & 1,4 & 0,2 & 0,02 & 5,7 & 4,6 \\
\hline Tratamento & $115,9 * *$ & $82,2 * *$ & $17,1^{* *}$ & $65,1 * *$ & $46,0 * *$ & $25,2 * *$ & $14,7 * *$ & $0,5^{\text {ns }}$ & $2,5^{*}$ & $11,4 * *$ & $21,1^{* *}$ & $4,4 * *$ & 18,0 ** & $11,5^{* *}$ \\
\hline Regressão & $\mathrm{Q}^{* *}$ & $\mathrm{~L}^{* *}$ & $\mathrm{~L}^{* *}$ & $\mathrm{~L}^{* *}$ & $\mathrm{~L}^{* *}$ & $\mathrm{Q}^{* *}$ & $\mathrm{~L}^{* *}$ & $\mathrm{~L}^{\mathrm{ns}}$ & $\mathrm{Q}^{*}$ & $\mathrm{Q}^{* *}$ & $\mathrm{Q}^{* *}$ & $\mathrm{Q}^{*}$ & $\mathrm{Q}^{* *}$ & $\mathrm{Q}^{* *}$ \\
\hline $\mathrm{R}^{2}$ & 0,98 & 0,96 & 0,91 & 0,97 & 0,98 & 0,93 & 0,76 & 0,52 & 0,84 & 0,29 & 0,68 & 0,30 & 0,94 & 0,99 \\
\hline Média $^{(2)}$ & $4,9 \mathrm{Aa}$ & $0,7 \mathrm{Aa}$ & $14,6 \mathrm{Bb}$ & $42,5 \mathrm{Ab}$ & $36,4 \mathrm{Ab}$ & $17,2 \mathrm{Aa}$ & $6,3 \mathrm{Aa}$ & $0,7 \mathrm{Ba}$ & $5,8 \mathrm{Ab}$ & $1,6 \mathrm{Aa}$ & $0,2 \mathrm{Aa}$ & $0,02 \mathrm{Aa}$ & $3,6 \mathrm{Aa}$ & $3,0 \mathrm{Ab}$ \\
\hline
\end{tabular}

${ }^{(1)}$ Dose percentual dos tratamentos em relação a fertirrigação da dose recomendada $[\mathrm{T} 4(100 \%)]$ de 140,40 e $130 \mathrm{~kg}$ ha ${ }^{-1}$ por ano de $\mathrm{N}, \mathrm{P}_{2} \mathrm{O}_{5}$ e $\mathrm{K}_{2} \mathrm{O}$, respectivamente. ${ }^{(2)}$ Médias seguidas de letras iguais, maiúsculas para profundidade e minúsculas para variedade, não diferem entre si pelo teste de Tukey, a

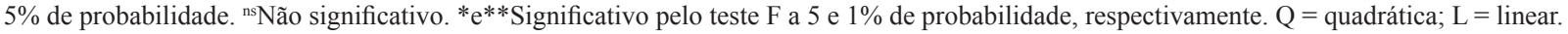


apresentam alto índice de salinidade; portanto, o aumento da dose aplicada desses fertilizantes, associado à aplicação localizada, pode promover danos salinos às plantas.

Segundo Dias et al. (2005), com auxílio dos extratores de solução por cápsulas porosas, é possível monitorar a concentração total de sais na solução do solo e manter a salinidade em nível desejado. $\mathrm{O}$ valor de condutividade elétrica limiar da solução do solo para a cultura do citros é de 1,4 $\mathrm{dS} \mathrm{m}^{-1}$ (Maas, 1993). Todos os valores de condutividade elétrica observados no tratamento T5 foram iguais ou superiores aos do limiar.

Quando se utiliza a técnica de fertirrigação em solos tropicais, é recomendada a aplicação de fertilizantes de melhor qualidade, com menor índice salino e, preferencialmente, com reação neutra ou ligeiramente alcalina; porém, esses fertilizantes têm custo mais elevado do que os convencionais. Há também a possibilidade de se trabalhar com um equilíbrio entre fontes (ácida e alcalina) que garantam a máxima eficiência econômica.

Os teores de N-NH $4, N-\mathrm{NO}_{3}, \mathrm{P}$ e $\mathrm{K}$ na solução do solo aumentaram com o aumento das doses aplicadas dos fertilizantes (Tabela 1). O aumento do teor de amônio na solução do solo, nos tratamentos T4 e T5, tanto a 30 como a $60 \mathrm{~cm}$ de profundidade, ocorreu em consequência da acidificação da solução do solo, que limitou o processo de nitrificação. Valores de $\mathrm{pH}$ baixos e má aeração desfavorecem o processo, pois os microrganismos responsáveis pela nitrificação são sensíveis à acidez e requerem valores de $\mathrm{pH}$ próximos da neutralidade, para a máxima atividade (Moreira \& Siqueira, 2006).

Segundo Dou et al. (1999), a forma absorvida - amônio ou nitrato - pode influenciar a resposta dos citros. Em ensaio com solução nutritiva, os autores mostraram que o fornecimento contínuo de amônio causou redução do crescimento de mudas de citrumeleiro 'Swingle' e tangerineira 'Cleópatra', em comparação ao fornecimento de nitrato. Estes autores verificaram sintomas de toxicidade de amônio a concentrações superiores a $15 \mathrm{mg} \mathrm{L}^{-1}$, com prejuízos à fotossíntese. $\mathrm{O}$ tratamento $\mathrm{T} 5$, mais acidificado, apresentou concentrações de amônio na solução do solo que chegaram a $67 \mathrm{mg} \mathrm{L}^{-1}$ (Tabela 1).

Se houver acidificação excessiva do bulbo de molhamento, principalmente com adubos que fornecem ou geram amônio na fase inicial, como ureia e sulfato e nitrato de amônio, haverá predominância no fornecimento de $\mathrm{NH}_{4}^{+}$para a laranjeira. Assim, poderá ocorrer desequilíbrio iônico, como consequência do excesso de cargas positivas disponíveis. Para ajustar o balanço de cargas, as plantas sintetizam ácidos orgânicos, por meio de exsudações radiculares (Mengel \& Kirkby, 1987). Isso acelera ainda mais a acidificação do solo, conforme observado por Quaggio (1991) em experimento de longa duração de resposta dos citros à calagem.

Costa et al. (2008), após três anos de aplicação contínua de doses elevadas de $\mathrm{N}$ em pastagem (200 e $300 \mathrm{~kg} \mathrm{ha}^{-1}$ ), com uso de fontes de sulfato de amônio e ureia, observaram que o $\mathrm{pH}$ do solo diminuiu de 5,6 para 4,6 , e os teores de $\mathrm{N}^{-\mathrm{NH}_{4}}$ no solo estavam mais elevados do que os de $\mathrm{N}^{-\mathrm{NO}_{3}}$. Ramos et al. (2010) verificaram que o carbono da biomassa microbiana do solo diminui após aplicação de ureia. Lange et al. (2006) comentam que a acidificação provocada por adubos nitrogenados não se restringe apenas à camada superficial, pois afeta também a subsuperfície do solo.

Como o nitrogênio deveria ser predominantemente absorvido na forma aniônica, ao ser absorvido com carga positiva pode acarretar prejuízos à absorção de outros cátions como cálcio, potássio e magnésio, em razão da inibição competitiva. Esta competição entre cátions, durante o processo de absorção, pode ser muito prejudicial para a laranjeira, pois uma das particularidades das plantas cítricas é o fato de a concentração de Ca nas folhas ser superior à de outros nutrientes, inclusive a de nitrogênio; esta característica não é comum a outras culturas (Mattos Júnior et al., 2005).

Apesar de o tratamento T1 não ter fornecido fósforo, os valores observados deste nutriente na solução do solo, muitas vezes foram superiores aos observados nos tratamentos que receberam 25 e $50 \%$ de $\mathrm{P}$ (tratamentos T2 e T3). No tratamento T1, também ocorreram os maiores valores de $\mathrm{pH}(\mathrm{pH} \sim 5,9)$. O fósforo adsorvido à superfície dos óxidos hidratados de $\mathrm{Fe}$ e $\mathrm{Al}$ torna-se mais solúvel com o aumento do pH da solução (Raij \& Quaggio, 1990). No início do experimento, o solo já possuía altos valores de $\mathrm{P}\left(57 \mathrm{mg} \mathrm{dm}^{-3}\right)$ que, associado aos maiores valores de $\mathrm{pH}$ observados no tratamento $\mathrm{T} 1$, promoveram aumento da disponibilidade de $\mathrm{P}$ neste tratamento.

Segundo Raij (1991), os teores de P na solução do solo são baixos, em torno de 0,1 a $0,2 \mathrm{mg} \mathrm{L}^{-1}$, e, muitas vezes, inferiores a estes valores. Contudo, em todos os tratamentos e em ambas as áreas das variedades de copa estudadas, foram observadas concentrações na 
solução do solo superiores às citadas pelo autor, mesmo a $60 \mathrm{~cm}$ de profundidade. Isso ocorre em razão do fato que, na fertirrigação por gotejamento, os fertilizantes são aplicados de forma localizada, em menor superfície do solo, e os sítios de fixação de P são saturados mais rapidamente, o que resulta em maior concentração do nutriente, na solução do solo, e maior eficiência de uso na fertirrigação.

Os resultados obtidos por Souza (2006) mostraram maiores teores de P na solução do solo, em sistema de fertirrigação, em comparação ao sistema de adubação sólida convencional na citricultura. De acordo com Laurindo et al. (2010), esse efeito é ainda mais acentuado no sistema de gotejamento com uma linha de gotejadores por linha de plantas, em comparação ao de duas linhas ou a microaspersão, com alcance até a profundidade de $60 \mathrm{~cm}$.

Silva (2002) em um trabalho com extratores de cápsula de cerâmica porosa para coletar a solução do solo, observaram que era possível monitorar a concentração dos íons $\mathrm{NO}_{3}, \mathrm{~K}, \mathrm{Ca}, \mathrm{Mg}, \mathrm{Na}$ e $\mathrm{Cl}$ na solução; porém, esta metodologia não era adequada para o fósforo. Diferentemente destes autores, no presente experimento, a concentração de $\mathrm{P}$ na solução do solo, sempre se correlacionou de forma significativa aos tratamentos aplicados, principalmente à profundidade de $30 \mathrm{~cm}$, e apresentou altos valores de coeficiente de determinação (Tabela 1).

A concentração de $\mathrm{Ca}$ e $\mathrm{Mg}$ na solução do solo apresentou tendência de aumento em consequência dos tratamentos (Tabela 1). Tanto o $\mathrm{Ca}$ como o $\mathrm{Mg}$ foram fornecidos apenas via calagem e em quantidades iguais para todos os tratamentos. Em razão da maior acidificação, observada nos tratamentos que receberam as maiores doses de fertilizantes, o $\mathrm{Ca}$ e o $\mathrm{Mg}$, que normalmente ficam mais retidos ao complexo de troca, permaneceram livres na solução do solo com a diminuição das cargas negativas do solo dependentes de $\mathrm{pH}$, e ficaram passíveis de serem lixiviados. Situação semelhante foi observada por Delbem et al. (2011), porém com diminuição dos teores de $\mathrm{Ca}$ e $\mathrm{Mg}$ no solo, resultante da lixiviação, por causa dos baixos valores de $\mathrm{pH}$.

A concentração de enxofre na solução do solo variou de forma significativa em relação aos tratamentos, exceto à profundidade de $30 \mathrm{~cm}$, com a laranjeira 'Valência' (Tabela 1); porém, não apresentou relação definida com os tratamentos. Nos tratamentos com menores valores de $\mathrm{pH}$, esperavam-se baixos teores de $\mathrm{S}$ na solução, pois a adsorção de sulfato no solo aumenta quando diminui o $\mathrm{pH}$ (Raij, 1991). Contudo, as menores concentrações foram observadas em $\mathrm{T} 1$, que apresentou o maior $\mathrm{pH}$.

A queda nos valores de $\mathrm{pH}$, em consequência das doses de N, P e K aplicadas, promoveu o aumento dos valores de B, Mn e Zn na solução do solo, nas duas profundidades e variedades estudadas, sendo que foram aplicados em doses iguais em todos os tratamentos.

Os teores de $\mathrm{Cu}$ e Fe, na solução do solo, apesar de terem apresentado diferença significativa entre os tratamentos aplicados, exceto para o Fe na laranjeira 'Hamlin' à profundidade de $30 \mathrm{~cm}$ (Tabela 1), ficaram sempre muito próximos, o que mostra pouca alteração em razão da queda de $\mathrm{pH}$. Estes dois micronutrientes foram observados em baixas concentrações na solução do solo, independentemente do tratamento e variedade de copa, em torno de 0,2 e $0,02 \mathrm{mg} \mathrm{L}^{-1}$, respectivamente para $\mathrm{Cu}$ e Fe. Esse resultado contrasta com o da análise do solo realizada em maio de 2009, em que foram observados altos teores de $\mathrm{Cu}$ e $\mathrm{Fe}$, respectivamente 1,4 e $59 \mathrm{mg} \mathrm{dm}^{-3}$ (valores médios a 0-60 $\mathrm{cm}$ de profundidade). Essa diferença pode indicar que a técnica de análise da solução do solo, com uso de extratores de cápsula porosa, pode não ser adequada para avaliar a disponibilidade destes nutrientes.

Considerando-se a profundidade efetiva de $60 \mathrm{~cm}$ do sistema radicular da laranja (Pires et al., 2005), não foram observadas perdas de nutrientes por lixiviação na solução do solo na média das variáveis analisadas durante os 11 meses de amostragem, no presente ensaio (Tabela 1). Segundo Raij (1991), as perdas mais importantes de nutrientes, em regiões de clima úmido, ocorrem por lixiviação, problema difícil de ser evitado, a não ser quando se parcelam as adubações, a fim de suprir os nutrientes em épocas de maior demanda pela planta, principalmente no caso do nitrato, que é facilmente perdido na água de percolação. $\mathrm{O}$ autor também comenta que, com exceção do $\mathrm{Cl}$, o B é o mais móvel dos micronutrientes e pode ser lixiviado principalmente em solos arenosos.

Os valores médios de $\mathrm{N}_{-} \mathrm{NO}_{3}$ e $\mathrm{B}$ na solução do solo, mantiveram-se semelhantes a 30 e a $60 \mathrm{~cm}$ de profundidade, para ambas as variedades (Tabela 1). Isso provavelmente ocorreu em razão do grande parcelamento da adubação empreendido, que é uma das principais vantagens da fertirrigação. Porém, valores similares entre as profundidades de 30 e $60 \mathrm{~cm}$, como os observados para $\mathrm{K}, \mathrm{N}-\mathrm{NO}_{3}$ e $\mathrm{B}$, geram preocupação, 
pois mostram alto potencial de perda por lixiviação, principalmente nos meses mais chuvosos do ano.

Precipitações pluviais elevadas, como as que ocorreram nos meses de janeiro de 2008 e janeiro e fevereiro de 2009, respectivamente de 268, 253 e $208 \mathrm{~mm}$, promoveram queda na concentração de nutrientes na solução e geraram perdas por lixiviação. Isso pode ser observado na Figura 1, que mostra as concentrações de $\mathrm{N}_{-} \mathrm{NO}_{3}$, $\mathrm{K}$ e B na solução do solo, de outubro de 2008 a maio de 2009, na área da laranjeira 'Valência'. Nos períodos mais chuvosos, foram observadas menores concentrações destes nutrientes na solução do solo e maiores valores à profundidade de $60 \mathrm{~cm}$.

Em geral, maiores concentrações de nutrientes foram observadas na solução do solo da área com 'Valência', o que mostra que a combinação de copa/porta-enxerto nessa cultivar teria absorvido menos nutrientes. A 'Valência' é de ciclo tardio, enquanto a 'Hamlin' é de ciclo precoce. Pozzan \& Tribone (2005) comentaram que, após a abertura das flores e a queda das pétalas, a
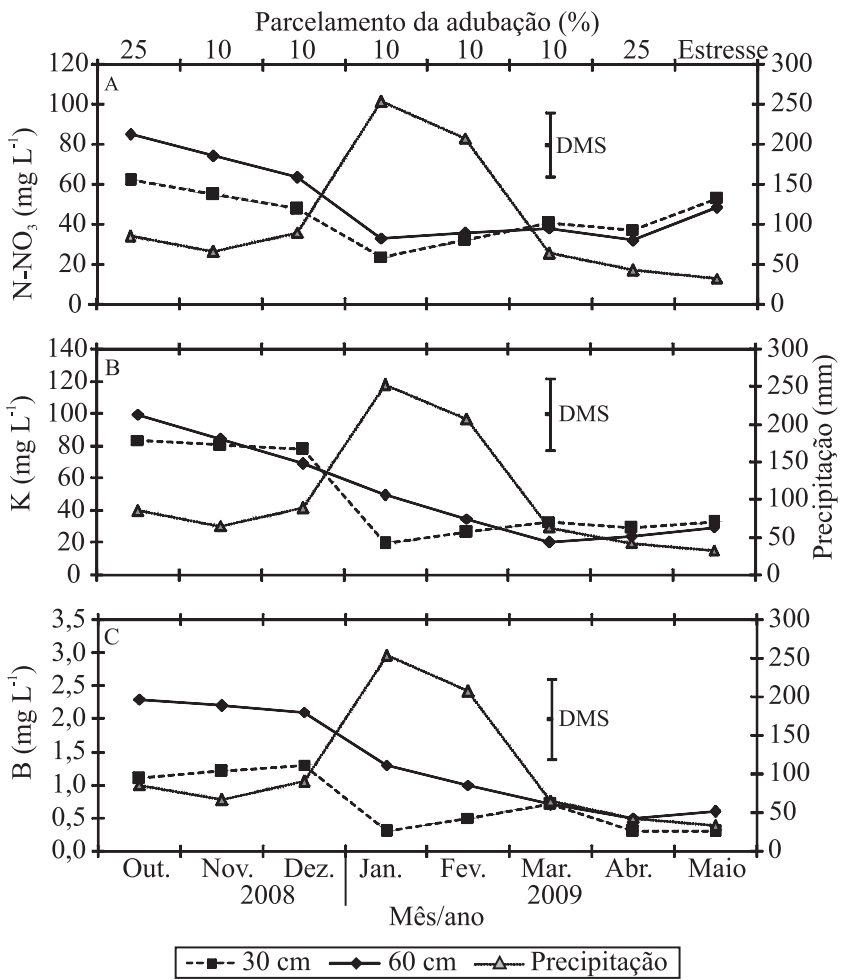

Figura 1. Concentração de nitrato, potássio e boro na solução do solo, nas profundidades de 30 e $60 \mathrm{~cm}$, e valores de precipitação, de outubro de 2008 a maio de 2009, na área com variedade de copa Valência. velocidade de transformações bioquímicas dos frutos é maior em cultivares precoces, o que exige maiores quantidades de nutrientes. Portanto, os projetos de fertirrigação devem ser preparados para permitir flexibilidade de atuação específica por variedade de laranja, que requerem quantidades e proporções nutricionais distintas ao longo do ano.

A produtividade, ao final do experimento, na safra 2008/2009, apresentou ajuste quadrático às doses de N, $\mathrm{P}$ e K aplicadas via fertirrigação, independentemente da variedade estudada (Figura 2). Nas funções ajustadas, os valores máximos de produção foram de 39 e $33 \mathrm{Mg}$ ha $^{-1}$, que corresponderam, respectivamente, a $135 \%$ (doses de 189, 54 e $176 \mathrm{~kg} \mathrm{ha}^{-1}$ ) e 138\% (doses de 193, 55 e $179 \mathrm{~kg} \mathrm{ha}^{-1}$ ) das doses de N, P e K recomendadas, para as laranjeiras 'Valência' e 'Hamlin'.

Os valores de produção observados em ambas as cultivares podem ser considerados baixos, para pomares irrigados e com fertirrigação. Isso, provavelmente, ocorreu como consequência dos problemas de acidificação observados na solução do bulbo úmido, gerados pelos tratamentos aplicados. Os baixos valores de $\mathrm{pH}$, encontrados nos tratamentos que receberam as maiores doses de N, P e K, alteraram a dinâmica dos nutrientes na solução do solo, e isso teria refletido de forma direta na produção.

Com o objetivo de estabelecer valores adequados de nutrientes na solução do solo, foram determinadas as concentrações de N, P e K na solução, à profundidade de $30 \mathrm{~cm}$, quando se obteve a máxima produção (Figura 3). Os teores de nitrato, P e K na solução do solo

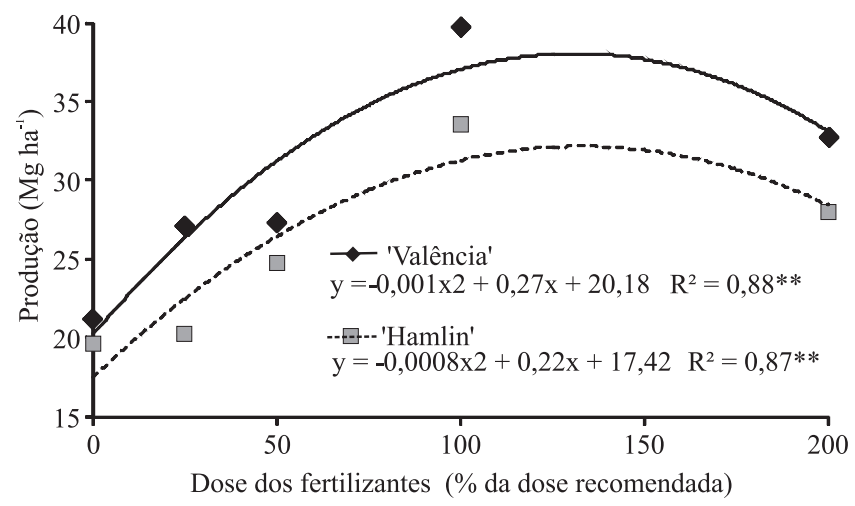

Figura 2. Produção das laranjeiras 'Valência' e 'Hamlin', de acordo com os tratamentos aplicados. A dose recomendada (100\%) equivale a 140, 40 e $130 \mathrm{~kg} \mathrm{ha}^{-1}$ de N, P e K, respectivamente. 

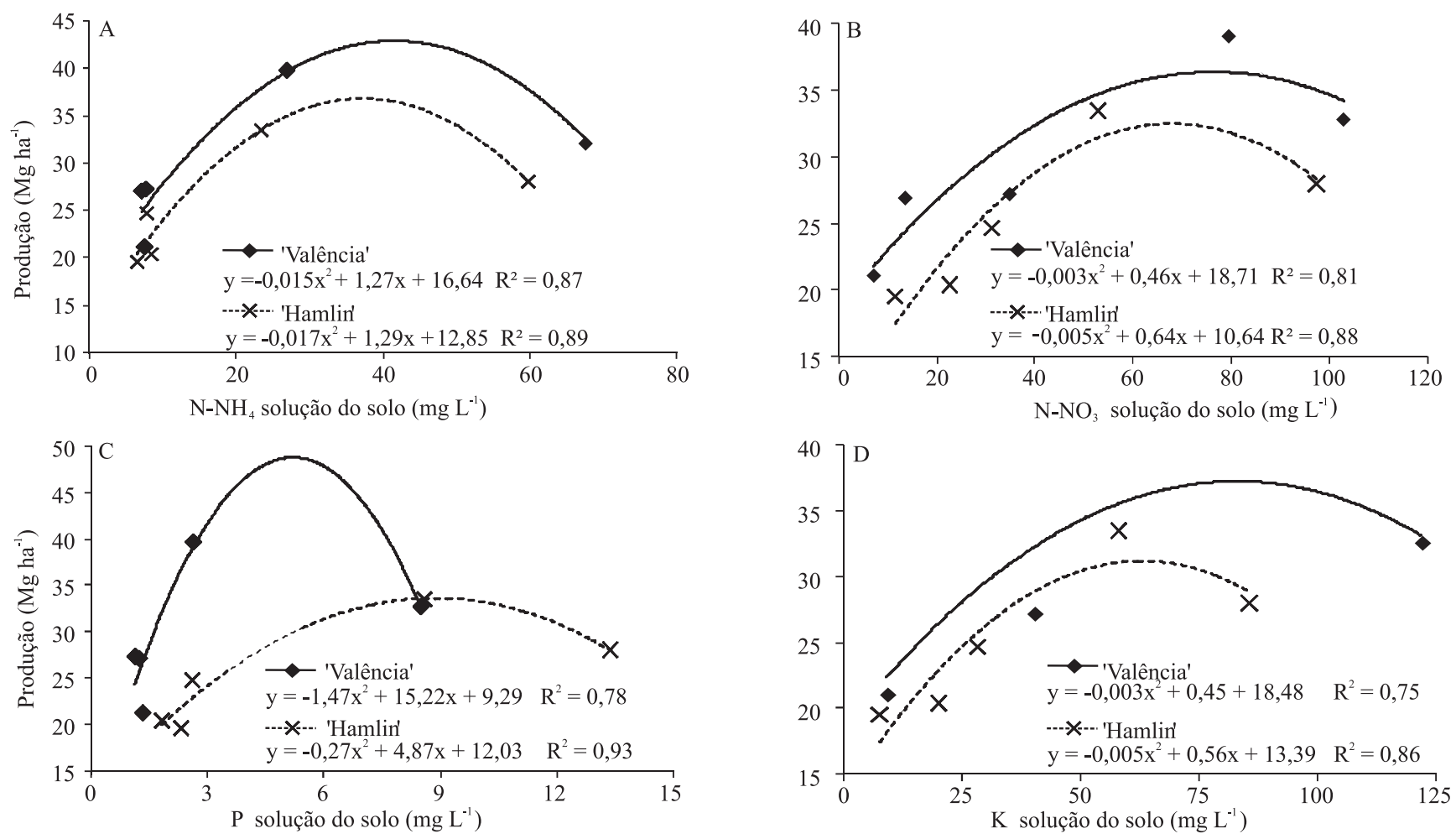

Figura 3. Produtividade de laranjeiras 'Valência' e 'Hamlin', em função das concentrações de amônio, nitrato, fósforo e potássio na solução do solo.

ficaram em torno de 77,5 e $75 \mathrm{mg} \mathrm{L}^{-1}$, respectivamente, para 'Valência'. Para 'Hamlin', estes valores foram de 64, 9 e $56 \mathrm{mg} \mathrm{L}^{-1}$. Quanto à concentração de amônio na solução do solo, foram observados $40 \mathrm{mg} \mathrm{L}^{-1}$, em média, na máxima produção (Figura 3), o que indica que valores maiores podem ser prejudiciais à cultura. O valor de condutividade elétrica na solução do solo, para ambas as variedades, na máxima produção, foi de $1,2 \mathrm{dS} \mathrm{m}^{-1}$.

\section{Conclusões}

1. O aumento das doses de N, P e K aplicadas acidifica a solução do solo e aumenta sua condutividade elétrica e teores de amônio, nitrato, fósforo, potássio, manganês e zinco, independentemente da variedade de laranja e profundidade avaliada.

2. Nos meses com maior precipitação pluvial, há potencial de perda de nutrientes por lixiviação, principalmente de nitrato, potássio e boro.

3. Os projetos de fertirrigação devem ser preparados de forma específica para cada variedade de laranja.
4. A análise da solução do solo, obtida por extratores de cápsula porosa, pode ser considerada uma ferramenta auxiliar, para monitorar e avaliar a disponibilidade de nutrientes em sistemas de fertirrigação na citricultura, exceto para os micronutrientes cobre e ferro.

\section{Agradecimentos}

À Fundação de Amparo à Pesquisa do Estado de São Paulo, por concessão de bolsa e auxílio financeiro à pesquisa; ao Instituto Agronômico (Campinas), pelo apoio durante as análises; e à empresa Citrovita/ Votorantim, pela contribuição no desenvolvimento deste trabalho.

\section{Referências}

ALlEN, R.G.; PEREIRA, L.S.; RAES, D.; SMITH, M. Crop evapotranspiration: guidelines for computing crop water requirements. Roma: FAO, 1998. 300p. (FAO. Irrigation and drainage paper, 56). 
BARROS, A.C.; FOLEGATTI, M.V.; SOUZA, C.F.; SANTORO, B.L. Distribuição da solução no solo aplicado por gotejamento enterrado e superficial. Irriga, v.15, p.361-372, 2010.

CAMARGO, O.A. de; MONIZ, A.C.; JORGE, J.A.; VALADARES, J.M.A.S. Métodos de análise química, mineralógica e física de solos do Instituto Agronômico de Campinas. Campinas: Instituto Agronômico, 1986. 94p. (IAC. Boletim técnico, 106).

COSTA, K.A. de P.; FAQUIM, V.; OLIVEIRA, I.P. de; RODRIGUES, C.; SEVERINO, E. da C. Doses e fontes de nitrogênio em pastagem de capim-marandu. I - Alterações nas características químicas do solo. Revista Brasileira de Ciência do Solo, v.32, p.1591-1599, 2008.

DELBEM, F.C.; SCABORA, M.H.; SOARES FILHO, C.V.; HEINRICHS, R.; CROCIOLLI, C.A.; CASSIOLATO, A.M.R. Fontes e doses de adubação nitrogenada na atividade microbiana e fertilidade do solo cultivado com Brachiaria brizantha. Acta Scientiarum. Agronomy, v.33, p.361-367, 2011.

DIAS, N. da S.; DUARTE, S.N.; GHEYI, H.R.; MEDEIROS, J.F. de; SOARES, T.M. Manejo da fertirrigação e controle da salinidade do solo sob ambiente protegido, utilizando-se extratores de solução do solo. Revista Brasileira de Engenharia Agrícola e Ambiental, v.9, p.496-504, 2005.

DOU, H.; ALVA, A.K.; BONDADA, B.R. Growth and chloroplast ultrastructure of two citrus rootstock seedlings in response to ammonium and nitrate nutrition. Journal of Plant Nutrition, v.22, p.1731-1744, 1999.

DUENHAS, L.H.; VILLAS BÔAS, R.L.; SOUZA, C.M.P.; RAGOSO, R.A.; BULL, L.T. Fertirrigação com diferentes doses de NPK e seus efeitos sobre a produção e qualidade de frutos de laranja (Citrus sinensis O.) 'Valência'. Revista Brasileira de Fruticultura, v.24, p.214-218, 2002.

FERREIRA, D.F. SISVAR: um programa para análises e ensino de estatística. Revista Symposium, v.6, p.36-41, 2008.

LANGE, A.; CARVALHO, J.L.N. de; DAMIN, V.; CRUZ, J.C.; MARQUES, J.J. Alterações em atributos do solo decorrentes da aplicação de nitrogênio e palha em sistema semeadura direta na cultura do milho. Ciência Rural, v.36, p.460-467, 2006.

LAURINDO, V.T.; SILVA, G.O.; PAVANI, L.C.; QUAGGIO, J.A. Padrão de distribuição de $\mathrm{K}, \mathrm{Ca}, \mathrm{Mg}$ e $\mathrm{P}$ no solo de um pomar de citros em função da fertirrigação. Engenharia Agrícola, v.30, p.909-921, 2010.

MAAS, E.V. Salinity and citriculture. Tree Physiology, v.12, p.195-216, 1993.

MATTOS JUNIOR, D.; BATAGLIA, O.C.; QUAGGIO, J.A. Nutrição dos citros. In: MATTOS JUNIOR, D. de; DE NEGRI, J.D.; PIO, R.M.; POMPEU JÚNIOR, J. (Ed.). Citros. Campinas: Instituto Agronômico: Fundag, 2005. p.197-219.

MENGEL, K.; KIRKBY, E.A. Principles of plant nutrition. $4^{\text {th }}$ ed. Bern: International Potash Institute, 1987. 687p.

MORAES, J.F.V.; DYNIA, J.F. Uso de cápsulas porosas para extrair solução do solo. Pesquisa Agropecuária Brasileira, v.25, p.1523-1528, 1990.
MOREIRA, F.M.S.; SIQUEIRA, J.O. Microbiologia e bioquímica do solo. 2.ed. Lavras: Universidade Federal de Lavras, 2006. $729 \mathrm{p}$.

PIRES, R.C.M.; LUCHIARI, D.J.F.; ARRUDA, F.B.; MOSSAK, I. Irrigação. In: MATTOS JUNIOR, D. de; DE NEGRI, J.D.; PIO, R.M.; POMPEU JUNIOR, J. (Ed.). Citros. Campinas: Instituto Agronômico: Fundag, 2005. p.369-408.

POZZAN, M.; TRIBONI, H.R. Colheita e qualidade do fruto. In: MATTOS JUNIOR, D. de; DE NEGRI, J.D.; PIO, R.M.; POMPEU JÚNIOR, J. (Ed.). Citros. Campinas: Instituto Agronômico: Fundag, 2005. p.801-822.

QUAGGIO, J.A. Repostas da laranjeira Valencia (Citrus sinnensis L. Osbeck) sobre limoeiro Cravo (Citrus limonia L. Osbeck) a calagem e ao equilíbrio de bases num latossolo vermelho escuro de textura argilosa. 1991. 107p. Tese (Doutorado) - Escola Superior de Agricultura Luiz de Queiroz, Universidade de São Paulo.

QUAGGIO, J.A.; MATTOS JUNIOR, D.; CANTARELLA, H. Manejo da fertilidade do solo na citricultura. In: MATTOS JUNIOR, D. de; DE NEGRI, J.D.; PIO, R.M.; POMPEU JÚNIOR, J. (Ed.). Citros. Campinas: Instituto Agronômico: Fundag, 2005. p.483-507.

RAIJ, B. van. Fertilidade do solo e adubação. Piracicaba: Agronômica Ceres: Potafos, 1991. 343p.

RAIJ, B. van; ANDRADE, J.C. de; CANTARELLA, H.; QUAGGIO, J.A. Análise química para avaliação da fertilidade de solos tropicais. Campinas: Instituto Agronômico, 2001. 285 p.

RAIJ, B. van; QUAGGIO, J.A. Extractable phosphorus availability indexes as affected by liming. Communications in Soil Science and Plant Analysis, v.21, p.1267-1276, 1990.

RAMOS, M.L.G.; CARVALHO, J.G.; RIBEIRO JÚNIOR, W.Q.; FERRAZ, D.M.M.; CARVALHO, A.M. de; AMÁBILE, R.F. Efeitos de doses de nitrogênio via fertirrigação na dinâmica microbiana, em solo cultivado com trigo. Bioscience Journal, v.26, p.376-383, 2010

SILVA, E.F.F. Manejo da fertirrigação e controle da salinidade na cultura do pimentão utilizando extratores de solução do solo. 2002. 136p. Tese (Doutorado) - Escola Superior de Agricultura Luiz de Queiroz, Piracicaba.

SOUZA, T.R. de. Dinâmica de nutrientes no perfil do solo em sistemas de adubação sólida e fertirrigação na citricultura. 2006. 91p. Dissertação (Mestrado) - Instituto Agronômico de Campinas, Campinas.

SOUZA, T.R. de; QUAGGIO, J.A.; SILVA, G.O. Dinâmica de íons e acidificação do solo nos sistemas de fertirrigação e adubação sólida na citricultura. Revista Brasileira de Fruticultura, v.28, p.501-505, 2006 .

WOLT, J.D. Soil solution chemistry: applications to environmental science and agriculture. New York: John Wiley, 1994. 345p.

$\overline{\text { Recebido em } 19 \text { de setembro de } 2011 \text { e aprovado em } 18 \text { de abril de } 2012}$ 